\section{CONVENIENT ROOT CANAL TREATMENT}

The new version 5.2 of Sirona Dental Systems' SiroEndo software allows more effective and convenient root canal treatment. As soon as the clinician reaches the apex they can reverse the rotation of the file - either on the SiroEndo unit or via the foot control. Just one brief touch is enough to change from clockwise to counterclockwise rotation and vice versa.

The new apex indicator keeps the user informed at all times. The exponential progress bar now consists of eighteen blocks as opposed to six. It indicates the distance between the file tip and the apex. When the file tip reaches the apex an 'A' is displayed. The

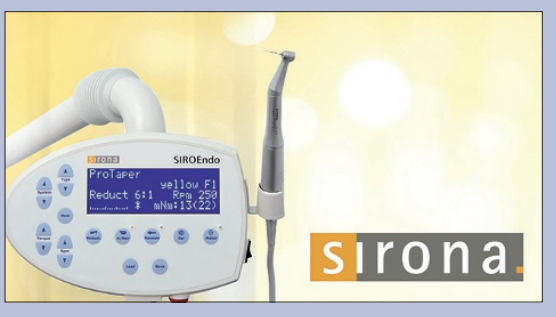

message ' -1 ' is shown as soon as the tip extends beyond the apex.

This is accompanied by differentiated acoustic signals. A series of short beeps can be heard as the file approaches the apex. This changes to a continuous tone when the file tip goes beyond the apex.

Reader response number 54

\section{INTERNET VISIBILITY}

A new website, PracticeSearch (www. practicesearch.com) has been developed by a dental surgeon as an internet portal containing the details of more than 1,400 dental websites together with a facility for dental practice details to be entered in an internet directory.

The software identifies practices that have gained third party accreditations such as the BDA Good Practice Scheme, Investors in People, Denplan Excel and Valident. Valident is a new regulatory compliance scheme designed to publicise on the internet dental practices that fulfil all of the regulatory requirements applying to electronic commerce the privacy of electronic communications, data protection and GDC Professional Standards. Reader response number 55

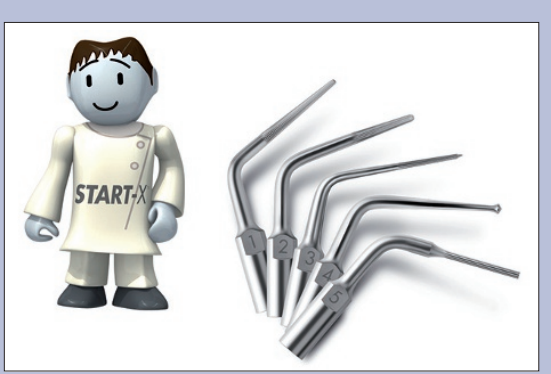

floor. Every Start-X tip has water ports on the inserts, which help cool the tips and avoid overheating of the treated tooth, particularly important during the high energy removal of metal posts. Reader response number 56

\section{LEARNING ONLINE}

The Dental Channel (www.dental-channel.co.uk) offers endodontics courses as part of its range of e-learning materials. Its CD-ROM 'Pulp afflictions - endodontics in primary dental care' covers orthograde treatment, retreatment, surgical endodontics, pulp therapy techniques for primary molars, and the management of traumatised incisors.

As part of its live webinar programme for 2010, Dr P. B. Robinson from Kings College London Dental Institute will present 'Endodontic update' on Wednesday 1 September at $8 \mathrm{pm}$. First time live webinar viewers receive a 50\% discount.

Currently, for a limited time, access to The Dental Channel's library of on-demand webinars including 'Endodontics: diagnosis', 'Endodontics: obturation' and 'Endodontic update' is available at the price of $£ 100.00$ + VAT (usually £250.00 + VAT) which provides over 60 hours of verifiable CPD. All of the on-demand courses listed above are included in this subscription.

Reader response number 57

\section{ONLINE REFERRAL SYSTEM LAUNCHED}

Following the launch of a new website, www.endocare.co.uk, referring practioners are now able to refer patients via the internet with a referral proforma. This makes the complex referral process much easier and quicker.

EndoCare's endodontic specialists use the latest dental technologies to guarantee that your patient is returned to you quickly, painlessly and ready for treatment. The most important element for the team is that the referral process, and subsequent treatment, is as simple as it can be for both patient and professional, as well as maintaining good relationships with referring practitioners.

Reader response number $\mathbf{5 8}$ 